\title{
A large and invasive pleomorphic adenoma of nasal cavity: a rare case report and review of literatures
}

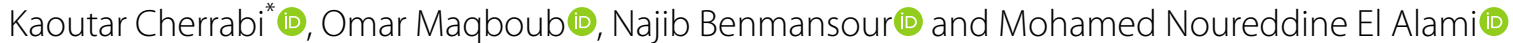

\begin{abstract}
Background: Pleomorphic adenomas are common tumors of major salivary glands. However, the localization in nasal cavity originating from the lateral wall is exceptional.

This work is a presentation of a very rare case that presents the diagnostic challenge, considering the multitude of malignant and benign differential diagnosis. A discussion of surgical approach, and the possible complications associated with it.

Case presentation: This is the case of an invasive nasal pleomorphic adenoma in a 48-year-old patient; the patient underwent complete excision through combined left lateral rhinotomy and functional endoscopic sinus surgery.

Conclusion: Pleomorphic adenoma is a very rare benign tumor of the nasal cavity. Clinical diagnosis is generally difficult regarding the multitude of differential diagnosis. Confirmation is established upon histological aspect.

This is a case of a very rare large pleomorphic adenoma of nasal cavity originating from the lateral wall, associated with differential diagnosis, and surgical approaches, as well as perceivable complications.

The strength of this work is to point out the importance of complete surgical extirpation and thorough follow-up to prevent recurrences and malignant transformation.
\end{abstract}

Keywords: Pleomorphic adenoma, Invasive, Nasal polyp, Radiology, Diagnosis, Differential, Rare, Surgical approach

\section{Background}

Pleomorphic adenoma is the most frequent benign tumors of major salivary glands as they present $65 \%$; the parotid is the most common site of predilection [1-6].

However, occurrence in secondary salivary glands is rare as they represent $8-10 \%$ of all forms; they are mainly in palate and oral cavity [3]. Pleomorphic adenoma of hypopharynx, glands of larynx, and trachea are rarer; localizations in lateral wall of nasal cavity is exceptional, with an incidence of only $1 \%[1,5,7]$.

\footnotetext{
*Correspondence: Kaoutarcherrabi.bz@gmail.com; cherrabi.kaoutar@gmail. com

ENT and Cervico-Facial Surgery Department, University hospital Hassan II,
} Fez, Morocco

\section{Case presentation}

A 48-year-old female presented with a chronic left nasal obstruction with progression span of 4 years, along with several episodes of small quantity epistaxis. She has been treated for chronic rhinitis, and her medical treatment was not successful. The patient presented with a nasal polyp; a biopsy was performed, which showed a pleomorphic adenoma.

Nasal endoscopy showed a pink grey polyp, occupying the totality of the left nasal cavity, as well as two thirds of right nasal cavity. The clinical exam of lacrimal ducts showed pus in the lacrimal puncta without local inflammatory signs (Fig. 1).

The patient underwent MRI of naso-sinus cavities, which showed a large tumor that occupied the totality of left nasal cavity, and the subtotality of the right cavity, 


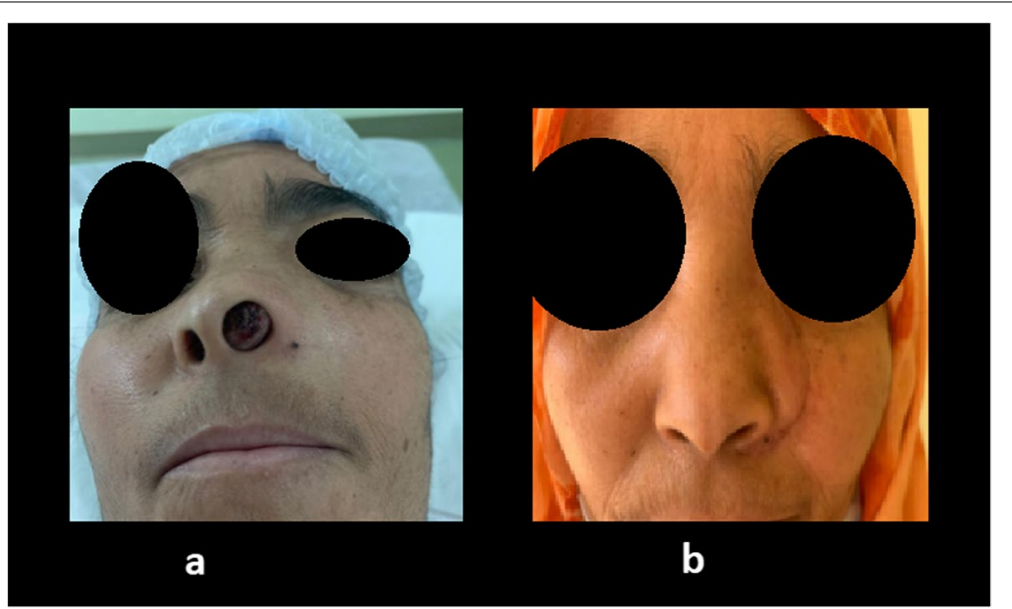

Fig. 1 Clinical findings. a Clinical findings showing nasal polyp exteriorized by left nasal orifice. b Clinical figure showing swelling of the anterior aspect of the left cheek

with several lobules separated by septae. The lesion was encapsulated, well-circumscribed, multi-lobulized, with moderately hyperintense signal in T2 weighted images and hyperintense signal in T1 weighted images with low apparent diffusion coefficient (ADC). The tumor presented a slow enhancement after gadolinium injection. In the left side, with retention to inferior and middle osteomeatal complex, and in the right side with middle osteomeatal complex (Fig. 2).

Blood test did not show any abnormalities: No systemic inflammatory response syndrome was there, nor was there any tumor lysis syndrome. The patient did not have any other lesions.

The patient underwent surgical excision through lateral rhinotomy, associated with endoscopic approach; the excision of the tumor was complete with clean margins, without any particular incidents. The follow-up was unremarkable.

\section{Discussion}

Pleomorphic adenoma of the nasal cavity is a very rare benign tumor more predominant in female patients in forth to sixth decade of life and could sometimes be found in teenagers [1-3]. No reports on occupational exposition to inhaled toxics are related to it [2].

Pleomorphic adenoma of the nasal septum is thought to originate from a remanence of the vomeronasal organ, from a misplaced ectodermal tissue, or from a viral infection $[1,4]$.

Stevenson et al. have stated that it is due to vomeronasal organ epithelial duct on cartilaginous nasal septum [4]. While Ersner and Satzman stipulate that during the migration of nasal buds, ectopic embryonic epithelialized cells that migrate are precursors for pleomorphic adenomas [4].

Generally, it is present ether in nasal septum or lateral wall: Since it is a slow growing tumor, symptoms only

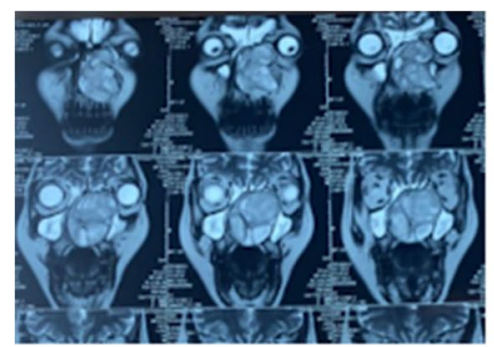

a

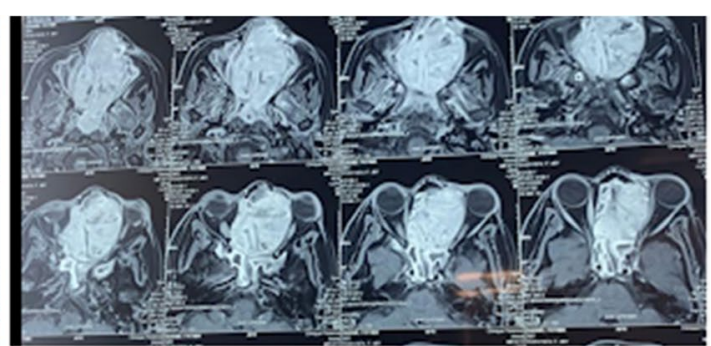

b

Fig. 2 Radiological findings in MRI. a Radiological findings of coronal sections. b Radiological findings of axial sections 
appear after a long silent period [2, 3]. Most frequently found symptoms are unilateral nasal obstruction, occasional bleeding, external deformity of nasal pyramids, and nasal swelling and pain $[1-3,5]$.

Endoscopic aspect: Clinically polypoid unilateral sessile and translucid, gray and pink polyp with regular surface and soft consistency $[2,4,8]$.

CT scan and MRI are important before surgery: While CT scan allows to define the tumors as well as signs of aggressive local extension [2], MRI shows a heterogeneous lesion that could also be isointense to brain tissue in T1 weighted sections, curvilinear enhancement with unenhanced small foci in fat-suppressed contrast enhanced T2 (cystic or myxoid component of tumor) $[2,7,9]$.

Pleomorphic adenomas are differential diagnosis to malignant mixed tumors [2] (Table 1).

Nasal pleomorphic adenoma differs from other localization in regard to its structure: They contain little cellularity with epithelial component, associated with high stromal component. Besides, they generally lack a capsule. Tumors are generally between 0.5 and $7 \mathrm{~cm}[1,2$, $4,7,8,10]$.

Immunohistochemical: Various cytokeratins, glial fibrillary acidic protein (GFAP), S100 protein, alpha smooth muscle actin, vimentin, and Ki67 proliferation marker $[1,2,7]$.
Main treatment is surgery; complete excision with clear margins is mandatory as it lowers the risk of recurrence $[2,10]$ (Table 2). Approach depends. Methods depend on size of the tumor and its location $[1,2,7]$.

Two main risks are associated with pleomorphic adenomas: recurrence and malignant transformation [1-3, 7].

\section{Recurrence and risk of malignant transformation}

Recurrences rate is of 7.5 to $8 \%[2,3]$. Potential risk of malignant transformation of pleomorphic adenomas is of $6 \%$ with a predilection to female patients [2]. This risk increases with delay in diagnosis. Most malignant tumors found in malignant transformations are squamous cell carcinoma and adenoid cystic carcinoma [2] as well as undifferentiated carcinoma and mucoepidermoid carcinoma [3].

Mechanisms of transformation are poorly understood; there is no consensus to predictive histological criteria. Immunohistochemical studies are shedding light: MUC1 is linked as a predictive factor to recurrence of pleomorphic adenoma. Besides, HMG1 and MDM2 may be genetic factors for malignant transformation [3].

As a result of incomplete excision, one case of metastasis was found after 17 years of follow-up [2, 7]. Spread through hematogeneous and or lymphatic routes are the most suspected etiologies [2].

Table 1 Differential diagnosis of pleomorphic adenoma: benign and malignant tumors. Macroscopic aspect [2, 5, 10]

\begin{tabular}{ll}
\hline $\begin{array}{l}\text { Malignant differential diagnosis of pleomorphic adenomas of nasal } \\
\text { cavity }[2, \mathbf{5}, \mathbf{1 0}] \text { : }\end{array}$ & $\begin{array}{l}\text { Benign differential diagnosis of pleomorphic adenomas of nasal cavity } \\
{[2] .}\end{array}$ \\
\hline - Epidermoid carcinoma & - Polyps \\
- Adenocarcinoma & - Papillomas (inverted papillomas included) \\
- Adenoid cystic carcinoma & - -Angiofibromas \\
- Melanoma & - Osteomas \\
- Olfactory esthesioneuroblastoma & \\
- Lymphomas & \\
\hline
\end{tabular}

Table 2 Surgical procedures possibilities in pleomorphic adenoma in nasal cavities

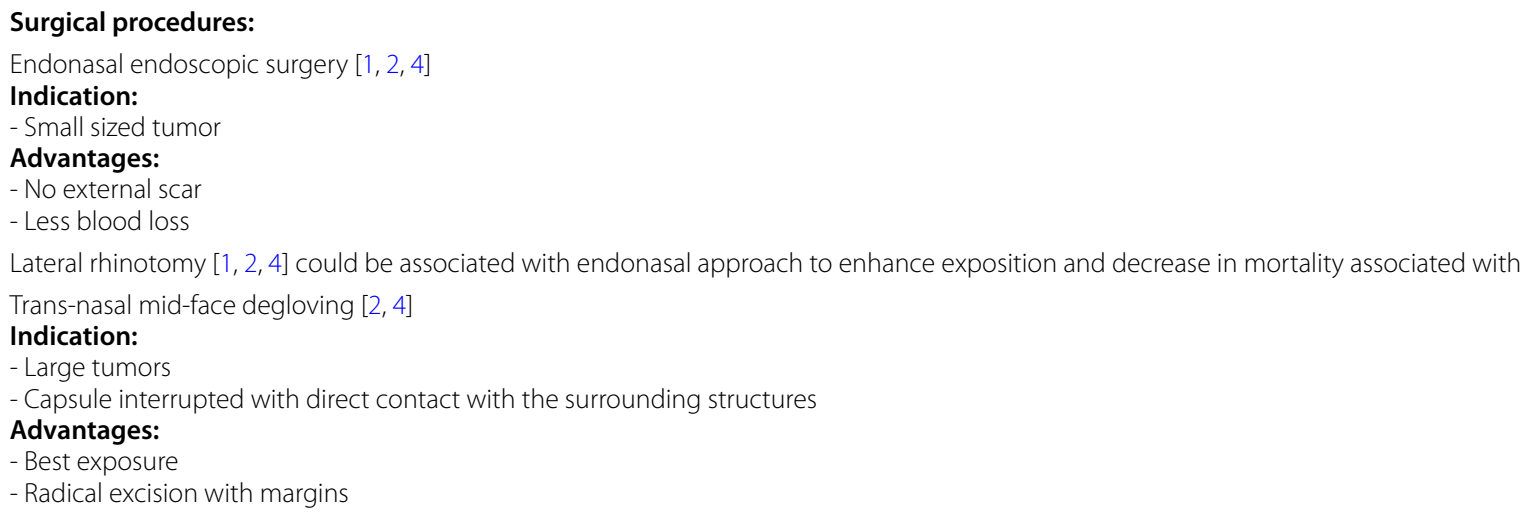


Risk factors of recurrence are an irregular or invaded capsule, as well as multi-nodularity [3]. Multiple recurrences also increase the risk for malignant transformation [3].

Long-term follow-up is essential for diagnosis of locoregional recurrences; CT scan and MRI are the best diagnostic tools after clinical suspicion of recurrence in endoscopic exam $[3,7]$.

\section{Conclusion}

Pleomorphic adenomas are very rare in accessory salivary glands; they are rarer in the nasal cavity where they generally originate from the nasal septum. Forms originating from the lateral wall of the nasal cavity are exceptional.

This work is a presentation of a very rare case of a large pleomorphic adenoma of nasal cavity. The tumor was extirpated with associated lateral rhinotomy and functional endoscopic nasal surgery with great outcome and follow-up. The case report is associated with a literature review of differential diagnosis and a summary of surgical approach and complications.

The take home message regarding this rare tumor is the importance of complete surgical extirpation and thorough follow-up to prevent recurrences and malignant transformation.

\section{Acknowledgements}

Not applicable.

\section{Authors' contributions}

K.C. conceived and designed the analysis, collected the data, performed the analysis, wrote the paper, and performed the surgery. O.M. contributed in the data collection. N.B performed the surgery. M.M supervised the designing analysis. All authors have read and agreed to its content.

\section{Funding}

Not applicable. No financial conflict of interest.

\section{Availability of data and materials}

Not applicable.

\section{Declarations}

Ethics approval and consent to participate

Not applicable

\section{Consent for publication}

The patient provided written consent to publish this case report, as well as for the publication of information.

\section{Competing interests}

The authors declare that they have no competing interests.

Received: 22 October 2021 Accepted: 3 December 2021

Published online: 10 January 2022

\section{References}

1. Wierzchowska M, Bodnar M, Burduk PK, Kaźmierczak W, Marszałek A (2015) Rare benign pleomorphic adenoma of the nose: short study and literature review. Wideochir Inne Tech Maloinwazyjne 10(2):332-336. https://doi.org/10.5114/wiitm.2014.47370

2. Sciandra D, Dispenza F, Porcasi R, Kulamarva G, Saraniti C (2008) Pleomorphic adenoma of the lateral nasal wall: case report. Acta Otorhinolaryngol Ital 28(3):150-153

3. Baron S et al (2014) Pleomorphic adenoma of the nasal septum. Eur Ann Otorhinolaryngol Head Neck Dis 131(2):139-141

4. Shetty S (2018) Dipak Ranjan Nayak, and Padmapriya Jaiprakash. Pleomorphic adenoma of nasal septum: a rare case. Case Rep 2018:bcr-2017

5. Hapunda R, Mumba C, Ngalamika O. Pleomorphic Adenoma Presenting as an Atypical Nasal Mass in a 26-Year-Old Female. Case Rep Surg. 2020;2020:3726397. https://doi.org/10.1155/2020/3726397.

6. Al Momen A, Al KA (2016) Pleomorphic adenoma of the nasal septum: a case report and review of the literature. Pan Arab J Rhinol 6:36-38

7. Acevedo JL et al (2010) Pleomorphic adenoma of the nasal cavity: a case report. Ear Nose Throat J 89(5):224-226

8. Ramana Reddy V, Reddy MKS, Srinivas B et al (1999) Benign mixed tumour (pleomorphic adenoma) of the nasal cavity. IJO HNS 51:66-67. https:// doi.org/10.1007/BF02996852

9. Motoori K et al (2000) Pleomorphic adenoma of the nasal septum: MR features. Am J Neuroradiol 21(10):1948-1950

10. Gana P, Masterson L (2008) Pleomorphic adenoma of the nasal septum: a case report. J Med Case Rep 2:349. https://doi.org/10.1186/ 1752-1947-2-349

\section{Publisher's Note}

Springer Nature remains neutral with regard to jurisdictional claims in published maps and institutional affiliations.

\section{Submit your manuscript to a SpringerOpen ${ }^{\circ}$ journal and benefit from:}

- Convenient online submission

- Rigorous peer review

- Open access: articles freely available online

- High visibility within the field

- Retaining the copyright to your article

Submit your next manuscript at $\boldsymbol{\nabla}$ springeropen.com 